\title{
Inhibition of the Growth of a Panel of Pathogenic Bacteria by Kunzea flavescens C.T.White and W.D.Francis Solvent Extractions
}

\author{
Getmore Rumbudzai Chikowe, ${ }^{a}$ Lindiwe Nomathemba Mpala, ${ }^{a}$ Ian Edwin Cock ${ }^{a} b^{*}$ \\ aSchool of Natural Sciences, Griffith University, 170 Kessels Rd, Nathan, Brisbane, Queensland 4111, AUSTRALIA. \\ bEnvironmental Futures Research Institute, Griffith University, 170 Kessels Rd, Nathan, Brisbane, Queensland 4111, AUSTRALIA.
}

\begin{abstract}
Introduction: Kunzea flavescens C.T.White \& W.D.Francis is a shrub that is native to eastern Australia. Several Kunzea spp. have been used as traditional medicines against bacterial pathogens. Despite this, K. flavescens leaf extractions have not been rigorously examined for growth inhibitory properties against many bacterial pathogens. Methods: The antimicrobial activity of $K$. flavescens leaf solvent extractions was investigated by disc diffusion and growth time course assays against a panel of pathogenic bacteria. The growth inhibitory activity was quantified by MIC determination. Toxicity was determined using the Artemia franciscana nauplii bioassay. Results: Methanolic, aqueous and ethyl acetate $K$. flavescens leaf extracts inhibited the growth of a wide range of bacterial species. Growth of both gram positive and gram negative bacteria was inhibited by the $K$. flavescens leaf extracts, although a higher proportion of gram positive species were susceptible. The methanolic extract was generally more potent than the aqueous or ethyl acetate extracts against all susceptible bacteria. The methanolic $K$. flavescens leaf extract was a particularly potent inhibitor of P. mirabilis and K. pneumoniae growth, with MIC values of 393 and $481 \mu \mathrm{g} / \mathrm{mL}$ respectively. The antibacterial activity of the methanolic $K$. flavescens leaf extract was further investigated by growth time course assays which showed significant growth inhibition in cultures of $K$. pneumoniae and
\end{abstract}

P. mirabilis within $1 \mathrm{~h}$ of exposure. All extracts were determined to be nontoxic in the Artemia franciscana nauplii bioassay, indicating their safety for internal use as well as for topical uses. Conclusions: The lack of toxicity of the $K$. flavescens leaf extracts and their growth inhibitory bioactivity against a panel of pathogenic bacteria indicate their potential in the development of novel antiseptic agents.

Key words: Kunzea flavescens, Myrtaceae, Autoimmune inflammatory disease, Rheumatoid arthritis, Ankylosing spondylitis, Terpenoid, Antibacterial activity, Medicinal plants.

\section{Correspondence:}

lan Edwin Cock

Environmental Futures Research Institute,

Griffith University, 170 Kessels Rd,Nathan,

Brisbane, Queensland 4111, AUSTRALIA.

Tel.: +61 737357637

Fax: +61737355282

E-mail: I.Cock@griffith.edu.au (I. E. Cock)

DOI: 10.5530/pc.2017.3.18

\section{INTRODUCTION}

Plants produce a wide variety of secondary metabolites which provide characteristic pigment, odour and flavour characteristics. In addition, these compounds may also provide the plants with protection against microbial challenge. ${ }^{1}$ Traditional plant derived medicines have been used for thousands of years in most parts of the world and with the increase in microbial antibiotic resistance, their use in fighting bacterial pathogens is becoming the focus of intense study. ${ }^{2,3}$ Whilst much of the research into traditional medicinal plant use has focused on Asian ${ }^{4}$, African $^{5}$ and South American ${ }^{6}$ plants, the therapeutic potential of the flora of Australia has also been recognised for thousands of years. The first Australians had well developed ethnopharmacological systems and understood the therapeutic properties of a wide variety of aromatic Australian plants. ${ }^{7}$ Despite this, relatively few studies have rigorously examined the antibacterial activity of Australian native plants, although there has been a recent increase in this field.

The healing properties of Australian plants of the family Myrtaceae have long been understood by Australian Aborigines. More recently, the bacterial growth inhibitory properties of many genera within the family Myrtaceae have been examined and documented. In particular, Callistemon spp. ${ }^{8}$, Eugenia spp. ${ }^{7}$, Kunzea spp. ${ }^{7,9}$, Leptospermum spp. ${ }^{7,10,11}$ and Syzygium spp. ${ }^{12-14}$ have been reported to inhibit the growth of a wide panel of bacteria, including many medicinally important pathogens. The genus Kunzea (family Myrtaceae) consists of approximately 50 species of small to medium shrubs which are native to Australia, with 2 species also occurring in New Zealand. Perhaps the best known Kunzea spp. are Kunzea ambigua (Sm.) Druce (commonly known as tick bush), Kunzea ericoides (A.Rich) Joy Thomps. (commonly known as Kānuka, white tea-tree, Burgan) and Kunzea pomifera F.Muell. (commonly known as muntries, emu apples, native cranberries). These species have each been reported to inhibit bacterial growth. ${ }^{7,9,15,16}$ However, most Kunzea spp. are yet to be screened for bacterial growth inhibitory activity and much work is required to examine the therapeutic potential of this genus.

Kunzea flavescens C.T.White \& W.D.Francis (Figure 1a) is a smallmedium shrub which is native to eastern Australia, especially in south east Queensland where it is usually found inhabiting rocky ridges in heathland and in open woodland. The shrub grows 1-4 $\mathrm{m}$ tall with crowded alternate, glabrous leaves which grow 4-8 mm long. White to cream flowers (approximately 10-13 mm diameter) usually develop from September to November. Interestingly, we were unable to find confirmed reports of Aboriginal medicinal use of any part of $K$. flavescens although other Kunzea spp. have documented uses in treating skin diseases including eczema, dermatitis and rashes. ${ }^{1,16}$ Many of these ailments are caused by microbial pathogens. Oils prepared from several Kunzea spp. have also been reported to ease the pain of insect bites, minor burns, headaches and inflammation. ${ }^{17}$ Despite this, antibacterial studies examining the growth inhibitory properties of $K$. flavescens are lacking.

Several interesting phytochemical components have been identified in Kunzea spp. extracts and essential oils. In particular, several terpenoid components including a-pinene (Figure 1b), 1,8-cineole (Figure 1c), bicyclogermacrene (Figure 1d), spathulenjol (Figure 1e), globulol (Figure 1f) and viridflorol (Figure 1g) have been identified in Kunzea spp. extracts and essential oils. ${ }^{15,18}$ Interestingly, those studies also reported broad spectrum antibacterial and anti-protozoal activity for the bark extracts and all of the isolated compounds. Indeed, the extract and isolated compounds inhibited the growth of all bacteria and protozoa screened. Broad spectrum antifungal activity was also reported, albeit at doses which would indicate only moderate to low growth inhibitory 


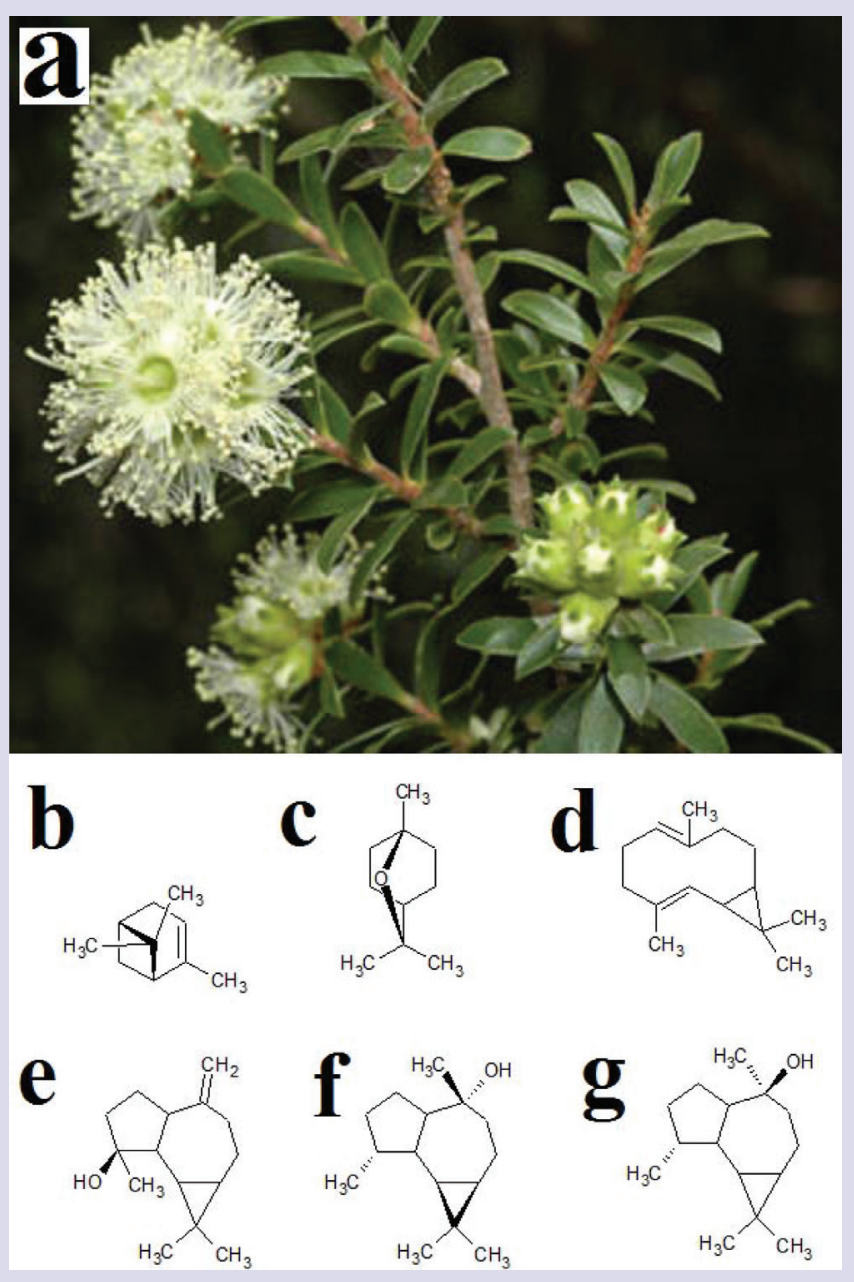

Figure 1: K. flavescens (a) leaves and flowers as well as the chemical structures of (b) a-pinene, (c) 1,8-cineole, (d) bicyclogermacrene, (e) spathulenjol, (f) globulol and (g) viridflorol.

activity. Despite these promising earlier studies, examination of the antibacterial properties and phytochemistry of many other Kunzea spp. including $K$. flavescens is lacking. The current report was undertaken to screen $K$. flavescens leaves for growth inhibitory properties against a panel of pathogenic bacteria.

\section{MATERIALS AND METHODS}

\section{Plant collection and extraction}

Kunzea flavescens C.T.White \& W.D.Francis leaves were obtained from and identified by Philip Cameron, senior botanic officer, Mt Cootha Botanical Gardens, Brisbane, Australia. The leaf samples were dried in a Sunbeam food dehydrator and stored at $-30^{\circ} \mathrm{C}$. Prior to use, the dried leaves were freshly ground to a coarse powder and $1 \mathrm{~g}$ quantities were weighed into separate tubes. A volume of $50 \mathrm{~mL}$ methanol, sterile deionised water, ethyl acetate, chloroform or hexane was added to individual tubes and extracted for 24 hours at $4{ }^{\circ} \mathrm{C}$ with gentle shaking. All solvents were obtained from Ajax, Australia and were AR grade. The extracts were filtered through filter paper (Whatman No. 54) under vacuum, followed by drying by rotary evaporation in an Eppendorf concentrator 5301. The resultant pellets were dissolved in $10 \mathrm{~mL}$ sterile deionised water (containing $1 \%$ DMSO). The extracts were passed through $0.22 \mu \mathrm{m}$ filter (Sarstedt) and stored at $4{ }^{\circ} \mathrm{C}$ until use.

\section{Qualitative phytochemical studies}

Phytochemical analysis of the K. flavescens leaf extracts for the presence of saponins, phenolic compounds, flavonoids, phytosteroids, triterpenoids, cardiac glycosides, anthraquinones, tannins and alkaloids was conducted by previously described assays. ${ }^{19-21}$

\section{Antibacterial screening \\ Test microorganisms}

All media was supplied by Oxoid Ltd., Australia. Reference strains of Klebsiella pneumoniae (ATCC31488), Escherichia coli (ATCC 25922) and Proteus mirabilis (ATCC21721) were purchased from American Tissue Culture Collection, USA. Clinical isolate microbial strains of Aeromonas hydrophilia, Alcaligenes feacalis, Bacillus cereus, Citrobacter freundii, Pseudomonas fluorescens, Salmonella newport, Serratia marcescens, Shigella sonneii, Staphylococcus aureus, Staphylococcus epidermidis and Streptococcus pyonenes were obtained from Ms Michelle Mendell and Ms Jane Gifkins, Griffith University. All stock cultures were subcultured and maintained in nutrient broth at $4^{\circ} \mathrm{C}$.

\section{Evaluation of antimicrobial activity}

Antimicrobial activity of all plant extracts was determined using a modified disc diffusion assay. ${ }^{22-24}$ Briefly, $100 \mu \mathrm{L}$ of each bacterial culture was grown in $10 \mathrm{~mL}$ of fresh nutrient broth until they reached a count of $\sim 10^{8}$ cells $/ \mathrm{mL}$. A volume of $100 \mu \mathrm{L}$ of the bacterial suspension was spread onto nutrient agar plates and extracts were tested for antibacterial activity using $5 \mathrm{~mm}$ sterilised filter paper discs. Discs were infused with $10 \mu \mathrm{L}$ of the plant extracts, allowed to dry and placed onto the inoculated plates. The plates were allowed to stand at $4{ }^{\circ} \mathrm{C}$ for $2 \mathrm{~h}$ before incubation at $30^{\circ} \mathrm{C}$ for $24 \mathrm{~h}$. The diameters of the inhibition zones were measured to the closest whole millimetre. Each assay was performed in at least triplicate. Mean values $( \pm$ SEM) are reported in this study. Standard discs of ampicillin $(10 \mu \mathrm{g})$ were obtained from Oxoid, Australia and were used as positive controls to compare antibacterial activity. Filter discs infused with $10 \mu \mathrm{L}$ of distilled water were used as a negative control.

\section{Minimum inhibitory concentration (MIC) determination}

The minimum inhibitory concentration (MIC) of each extract against susceptible bacteria was determined as previously described. ${ }^{25,26}$ Briefly, the $K$. flavescens leaf extracts were diluted in deionised water and tested across a range of concentrations. Discs were infused with $10 \mu \mathrm{L}$ of the test dilutions, allowed to dry and placed onto inoculated plates. The assay was completed as outlined above and graphs of the zone of inhibition versus concentration were plotted for each extract. Linear regression was used to determine the MIC values of each extract.

\section{Bacterial growth time course assay}

Bacterial growth time course studies were performed as previously described. ${ }^{27}$ Briefly, $3 \mathrm{~mL}$ of Klebsiella pneumoniae (ATCC31488) and Proteus mirabilis (ATCC21721) in nutrient broth were added individually to $27 \mathrm{~mL}$ nutrient broth containing $3 \mathrm{~mL}$ of $10 \mathrm{mg} / \mathrm{mL}$ methanolic and aqueous plant extract to give a final concentration of $1000 \mu \mathrm{g} / \mathrm{mL}$ in the assay. The tubes were incubated at $30{ }^{\circ} \mathrm{C}$ with gentle shaking. The optical density was measured hourly at $550 \mathrm{~nm}$ for a $6 \mathrm{~h}$ incubation period. Control tubes were incubated under the same conditions except without the extract. All assays were performed in triplicate.

\section{Toxicity screening}

\section{Reference toxin for toxicity screening}

Potassium dichromate $\left(\mathrm{K}_{2} \mathrm{Cr}_{2} \mathrm{O}_{7}\right)$ (AR grade, Chem-Supply, Australia) was prepared as a $4 \mathrm{mg} / \mathrm{mL}$ solution in distilled water and was serially 
Table 1: The mass of dried extracted material, the concentration after resuspension in deionised water and qualitative phytochemical screenings of the $K$. flavescens leaf extracts.

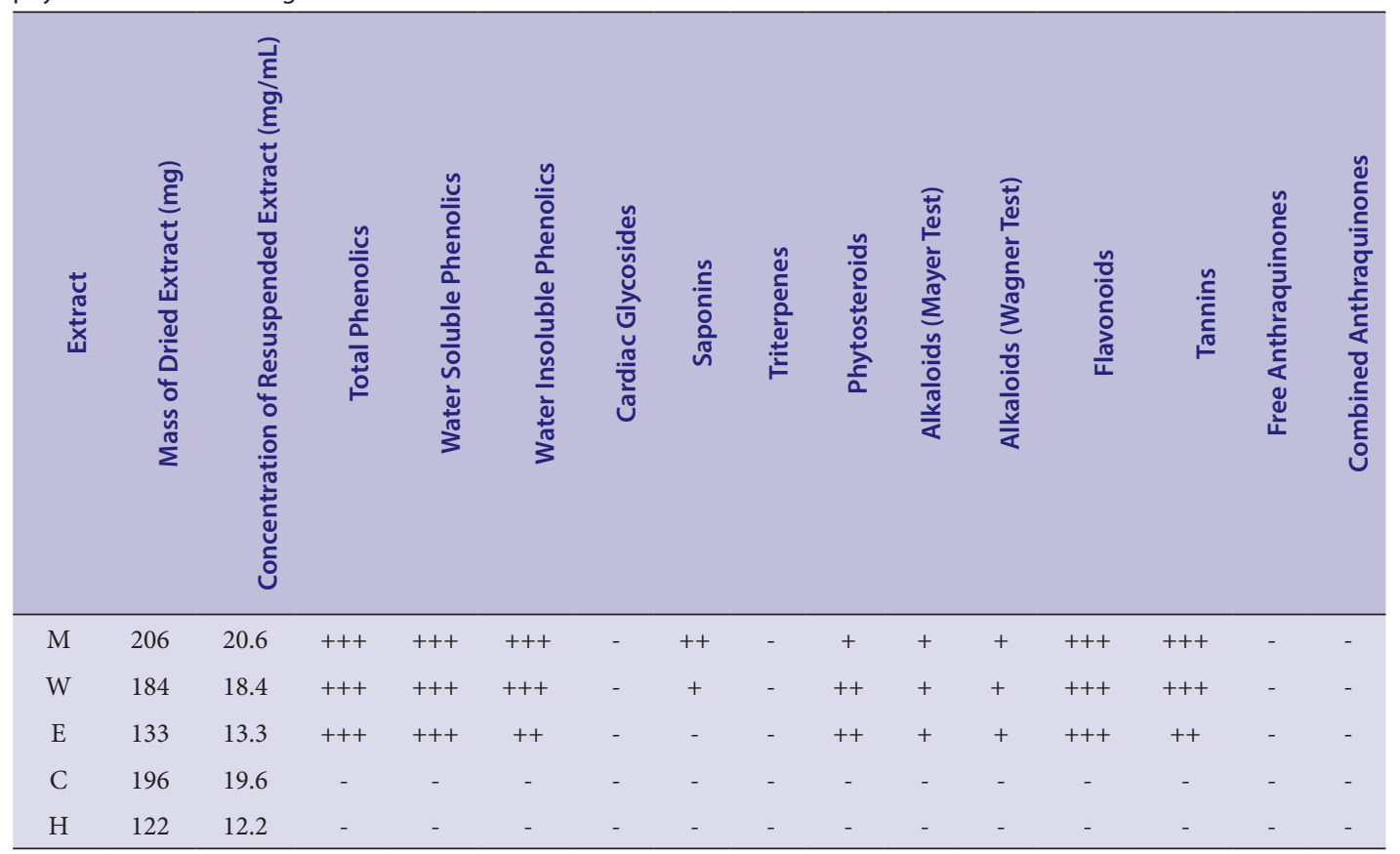

+++ indicates a large response; ++ indicates a moderate response; + indicates a minor response; - indicates no response in the assay. $\mathrm{M}=$ methanolic extract; $\mathrm{W}=$ aqueous extract; $\mathrm{E}=$ ethyl acetate extract; $\mathrm{H}=$ hexane extract.

diluted in artificial seawater for use in the Artemia franciscana nauplii bioassay.

\section{Artemia franciscana nauplii toxicity screening}

Toxicity was tested using an adapted Artemia franciscana nauplii lethality assay. ${ }^{28-30}$ Briefly, $400 \mu \mathrm{L}$ of seawater containing approximately 54 (mean $54.3, \mathrm{n}=75, \mathrm{SD} 12.6)$ A. franciscana nauplii were added to wells of a 48 well plate and immediately used for bioassay. A volume of $400 \mu \mathrm{L}$ of diluted plant extracts or the reference toxin were transferred to the wells and incubated at $25 \pm 1^{\circ} \mathrm{C}$ under artificial light (1000 Lux). A $400 \mu \mathrm{L}$ seawater negative control was run in triplicate for each plate. All treatments were performed in at least triplicate. The wells were checked at regular intervals and the number of dead were counted. The nauplii were considered dead if no movement of the appendages was detected within 10 seconds. After $24 \mathrm{~h}$, all nauplii were sacrificed and counted to determine the total \% mortality per well. The $\mathrm{LC}_{50}$ with $95 \%$ confidence limits for each treatment was determined using probit analysis.

\section{Statistical analysis}

Data are expressed as the mean \pm SEM of at least three independent experiments. One way ANOVA was used to calculate statistical significance between control and treated groups with a $P$ value $<0.01$ considered to be statistically significant.

\section{RESULTS}

\section{Liquid extraction yields and qualitative phytochemical screening}

Extraction of $1 \mathrm{~g}$ of dried and powdered $K$. flavescens leaf with solvents of varying polarity yielded dried extracts ranging from 122mg (hexane extract) to $206 \mathrm{mg}$ (methanolic extract) (Table 1). The aqueous (184 mg) and chloroform extracts $(196 \mathrm{mg}$ ) also yielded high levels of extracted materials. The dried extracts were resuspended in $10 \mathrm{~mL}$ of deionised water (containing 1\% DMSO), resulting in the extract concentrations shown in Table 1.

Qualitative phytochemical studies showed that the higher polarity methanol, water and ethyl acetate solvents extracted the greatest diversity and highest levels of phytochemicals. Each contained high levels of phenolics, flavonoids and tannins, as well as moderate levels of phytosterols and low levels of alkaloids. Interestingly, despite extracting relatively large amounts of material, the chloroform and hexane extracts were devoid of all classes of phytochemicals screened. Due to their nonpolar nature, these extracts would be expected to contain high levels of lipids, hydrocarbons etc. As our qualitative phytochemical studies did not screen for these compounds, they were not detected and other techniques are required to further examine the nature of these nonpolar components.

\section{Antimicrobial activity}

To determine the growth inhibitory activity of the $K$. flavescens leaf extracts against the panel of pathogenic bacteria, aliquots $(10 \mu \mathrm{L})$ of each extract were screened in the disc diffusion assay. The methanolic, aqueous and ethyl acetate $K$. flavescens leaf extracts inhibited 3 of the 10 gram negative bacterial species screened (Figure 2). The methanolic $K$. flavescens leaf extract was a more potent growth inhibitor than the aqueous or ethyl acetate extracts against all susceptible bacterial species (as assessed by the sizes of the zones of inhibition). The methanolic extract was a particularly potent inhibitor of $P$. mirabilis growth, with zones of inhibition of $12.3 \pm 0.9 \mathrm{~mm}$. This inhibition was particularly noteworthy compared to the inhibition by the ampicillin control $(10 \mu \mathrm{g}$ : inhibition zones of approximately $8.3 \pm 0.3 \mathrm{~mm}$ ). The aqueous and ethyl acetate $K$. flavescens leaf extracts were also good $P$. mirabilis growth inhibitors, with inhibition zones of $9.5 \pm 0.5 \mathrm{~mm}$ and $8.0 \pm 0.5 \mathrm{~mm}$ respectively. The chloroform extract also inhibited $P$. mirabilis growth, albeit with substantially smaller inhibition zones. The hexane extract was devoid of growth inhibitory activity.

$K$. pneumoniae was also highly susceptible to the $K$. flavescens leaf 


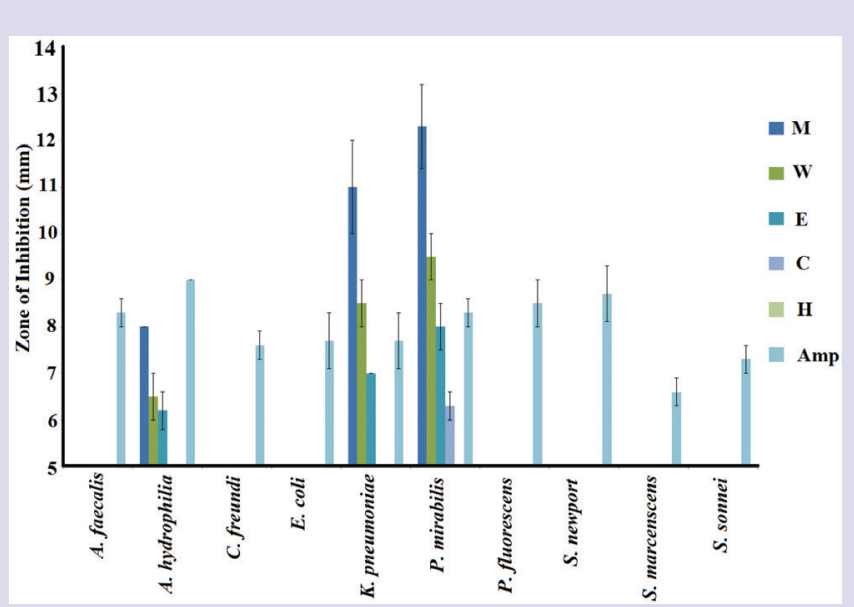

Figure 2: Growth inhibitory activity of $K$. flavescens leaf extracts against the gram negative bacterial species. $M=$ methanolic extract; $\mathrm{W}=$ aqueous extract; $\mathrm{E}=$ ethyl acetate extract; $\mathrm{C}=$ chloroform extract; $\mathrm{H}=$ hexane extract; Amp = ampicillin $(10 \mu \mathrm{g})$ control. All determinations were performed in triplicate and the results are expressed as mean zones of inhibition $(\mathrm{mm}) \pm \mathrm{SEM}$.

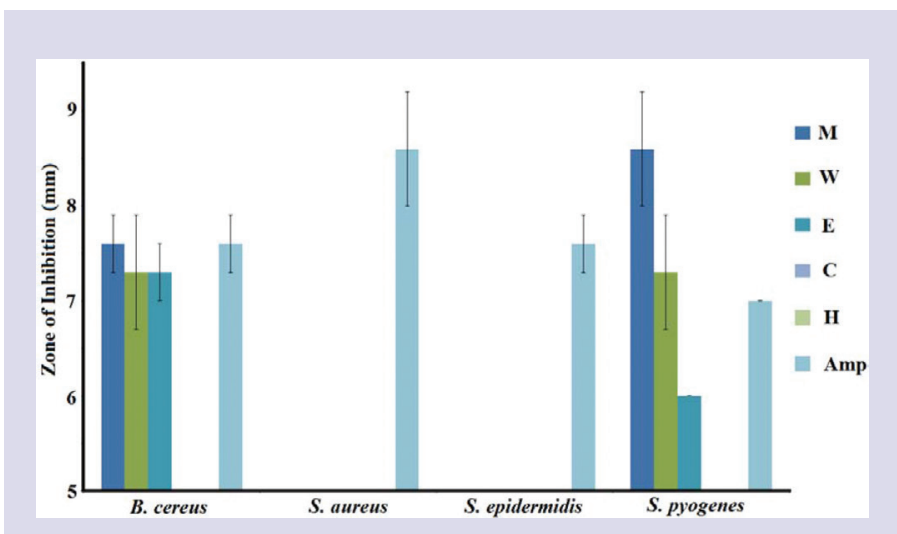

Figure 3: Growth inhibitory activity of $K$. flavescens leaf extracts against the gram positive bacterial species. $M=$ methanolic extract; $\mathrm{W}=$ aqueous extract; $\mathrm{E}=$ ethyl acetate extract; $\mathrm{C}=$ chloroform extract; $\mathrm{H}=$ hexane extract; $\mathrm{Amp}=$ ampicillin $(10 \mu \mathrm{g})$ control. All determinations were performed in triplicate and the results are expressed as mean zones of inhibition $(\mathrm{mm}) \pm$ SEM.

extracts. As reported for $P$. mirabilis growth inhibition, the methanolic extract was substantially more potent than the other extracts, with $11.0 \pm 1.0 \mathrm{~mm}$ zones of inhibition. Growth inhibition by the aqueous extract $(8.5 \pm 0.5 \mathrm{~mm})$ was also indicative of good growth inhibition. In contrast, the inhibition by the ethyl acetate extract $(7.0 \mathrm{~mm})$ was indicative of low to moderate growth inhibitory activity. Whilst $A$. hydrophilia was also susceptible to inhibition by the $K$. flavescens leaf extracts, the zones of inhibition were substantially smaller than for the other bacteria. Gram positive bacteria were also inhibited by the $K$. flavescens leaf extracts. Indeed, 2 of the 4 gram positive bacteria (50\%: B. cereus, $S$. pyogenes) were inhibited, with zones of inhibition consistent with low to moderate inhibition. Zones of $7.6 \pm 0.3 \mathrm{~mm}$ and $8.6 \pm 0.6 \mathrm{~mm}$ were determined for the methanolic $K$. flavescens leaf extract against $B$. cereus and $S$. pyogenes respectively. The aqueous and ethyl acetate extracts also inhibited these gram positive bacteria, although generally with substantially less potency (as judged by the size of the inhibition zone).

The antimicrobial efficacy was further quantified by determining the MIC values for each extract against the susceptible microbial species. The methanolic, aqueous and ethyl acetate $K$. flavescens leaf extracts were potent growth inhibitors of several bacterial species (as judged by MIC; Table 2). P. mirabilis was the most susceptible bacteria to the K. flavescens leaf extracts, with MIC values $<400 \mu \mathrm{g} / \mathrm{mL}$ ( $<4 \mu \mathrm{g}$ infused into the disc). The aqueous and ethyl acetate $K$. flavescens leaf extracts were also good $P$. mirabilis growth inhibitor, with MIC values $<850 \mu \mathrm{g} / \mathrm{mL}$. As $P$. mirabilis infection is a common cause of urinary tract infections and has also been identified as a trigger of rheumatoid arthritis [31,32], the methanolic, aqueous and ethyl acetate $K$. flavescens leaf extracts have potential for the prevention of these diseases in genetically susceptible individuals. Similarly, K. pneumoniae and S. pyogenes were also susceptible to growth inhibition by the methanolic, aqueous and ethyl acetate $K$. flavescens leaf extracts. As K. pneumoniae can trigger ankylosing spondylitis [33, 34] and $S$. pyogenes can trigger rheumatic heart disease $[35,36]$ in genetically susceptible individuals, these extracts also have potential to prevent and treat these diseases.

\section{Bacterial growth time course assay}

The antibacterial activity of the K. flavescens leaf extracts was further investigated in reference bacterial strains by bacterial growth time course assays in the presence and absence of each extract. Only the effect of the methanolic and aqueous extract on the bacterial growth time course were evaluated as these extracts were generally the most potent of the other $K$. flavescens leaf extracts. Furthermore, the time course studies only examined the effect of the extracts on K. pneumoniae and P. mirabilis as these were the most susceptible to inhibition by the $K$. flavescens leaf extracts. The starting concentration of the extract used in these assays was $1000 \mu \mathrm{g} / \mathrm{mL}$. The methanolic and aqueous $K$. flavescens extracts significantly inhibited K. pneumoniae (Figure 4a) and P. mirabilis (Figure $4 \mathrm{~b}$ ) growth within $1 \mathrm{~h}$, indicating a rapid antimicrobial action. Furthermore, the inhibition of both P. mirabilis and K. pneumoniae by the methanolic and aqueous $K$. flavescens leaf extracts was still significantly inhibited by the end of the $6 \mathrm{~h}$ time course study. This may indicate that these extracts have bactericidal activity against $P$. mirabilis and $K$. pneumoniae at the dose tested. Indeed, the turbidity at $6 \mathrm{~h}$ was not greatly increased from the starting turbidity.

\section{Quantification of toxicity}

The toxicity of the $K$. flavescens leaf extracts was initially tested in the Artemia franciscana nauplii bioassay at a concentration of $2000 \mu \mathrm{g} / \mathrm{mL}$ (Figure 5). All extracts induced low levels of mortality at $24 \mathrm{~h}$, similar to the $\%$ mortality seen for the seawater control. By $48 \mathrm{~h}$, the aqueous and methanolic extracts had begun to induce mortality significantly higher than that in the untreated control. As all of the extracts induced $<50 \%$ toxicity at $24 \mathrm{~h}$, all were deemed to be nontoxic. Extracts with an $\mathrm{LC}_{50}$ $>1000 \mu \mathrm{g} / \mathrm{mL}$ towards Artemia nauplii have previously been defined as being nontoxic [30]. In contrast, the potassium dichromate positive control induced mortality within $4 \mathrm{~h}$ (results not shown), with $100 \%$ mortality induction seen by $24 \mathrm{~h}$.

\section{DISCUSSION}

Plant derived remedies are becoming increasingly sought after in the treatment of a myriad of diseases and disorders due both to their perception of greater safety than synthetic drugs, and the failure of current drug regimens to effectively treat many diseases. Our study reports on the growth inhibitory properties of $K$. flavescens leaf extracts against a panel of pathogenic bacteria, and on their toxicity. Both gram positive 
Table 2: Minimum bacterial growth inhibitory concentration $(\mu \mathrm{g} / \mathrm{mL})$ of the $K$. flavescens extracts.

\begin{tabular}{|c|c|c|c|c|c|c|}
\hline & Bacteria & $M$ & w & E & C & $\mathrm{H}$ \\
\hline \multirow{10}{*}{ 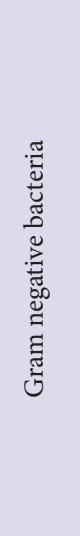 } & A. faecalis & - & - & - & - & - \\
\hline & A. hydrophilia & 1637 & 2320 & 1875 & - & - \\
\hline & C. freundi & - & - & - & - & _. \\
\hline & E. coli & - & - & - & - & - \\
\hline & K.pneumoniae & 481 & 887 & 946 & - & - \\
\hline & P. mirabilis & 393 & 804 & 837 & 3652 & - \\
\hline & P. fluroscens & - & - & - & - & - \\
\hline & S. newport & - & - & - & - & - \\
\hline & S. marcenscens & - & - & - & - & - \\
\hline & S. sonnei & - & - & - & - & - \\
\hline \multirow{4}{*}{ 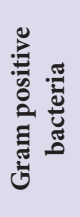 } & B. cereus & 1718 & 1562 & 1490 & - & _. \\
\hline & S. aureus & - & - & - & - & - \\
\hline & S. epidermidis & - & - & - & - & - \\
\hline & S. pyogenes & 1205 & 1950 & 1885 & - & 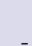 \\
\hline
\end{tabular}

Numbers indicate the mean $\mathrm{MIC}$ and $\mathrm{LC}_{50}$ values of triplicate determinations. - indicates no inhibition. $\mathrm{M}=$ methanolic extract; $\mathrm{W}=$ aqueous extract; $\mathrm{E}=$ ethyl acetate extract; $\mathrm{C}=$ chloroform extract; $\mathrm{H}=$ hexane extract.

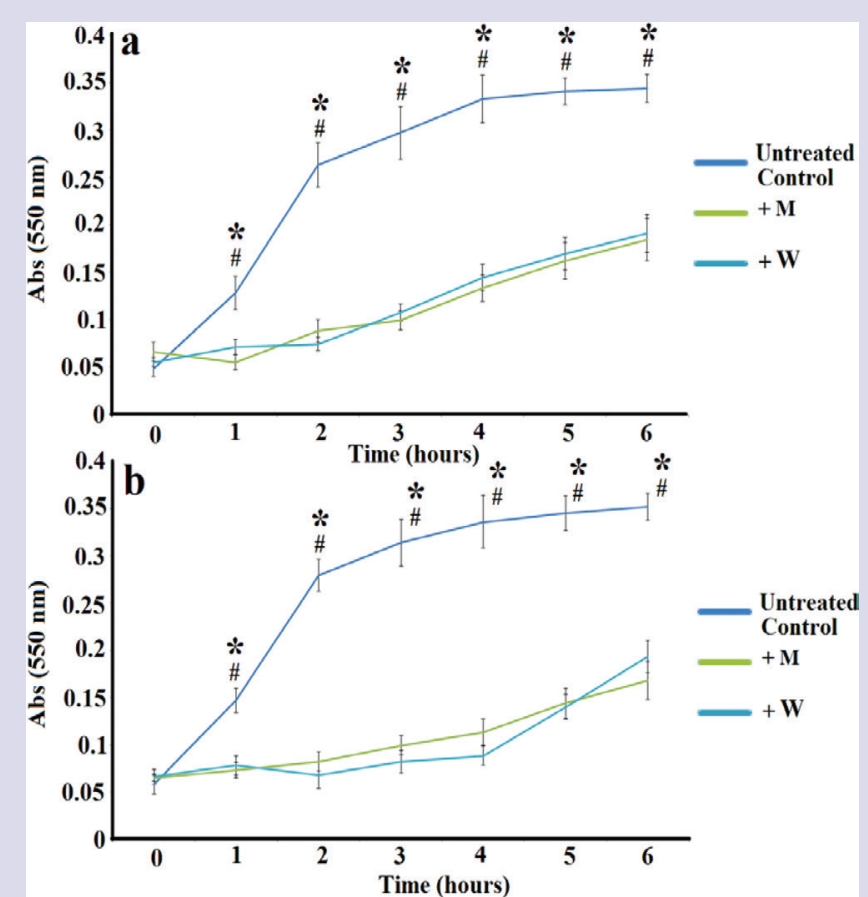

Figure 4: Bacterial growth curves for the methanolic and aqueous K. flavescens leaf extracts against (a) K. pneumoniae (ATCC31488) and (b) P. mirabilis (ATCC21721). All bioassays were performed in at least triplicate and are expressed as mean \pm SEM. ${ }^{*}=$ results that are significantly different between the between the growth in the presence of the methanolic extract and the untreated control growth $(p<0.01)$; $\#=$ results that are significantly different between the between the growth in the presence of the aqueous extract and the untreated control growth $(p<0.01)$.

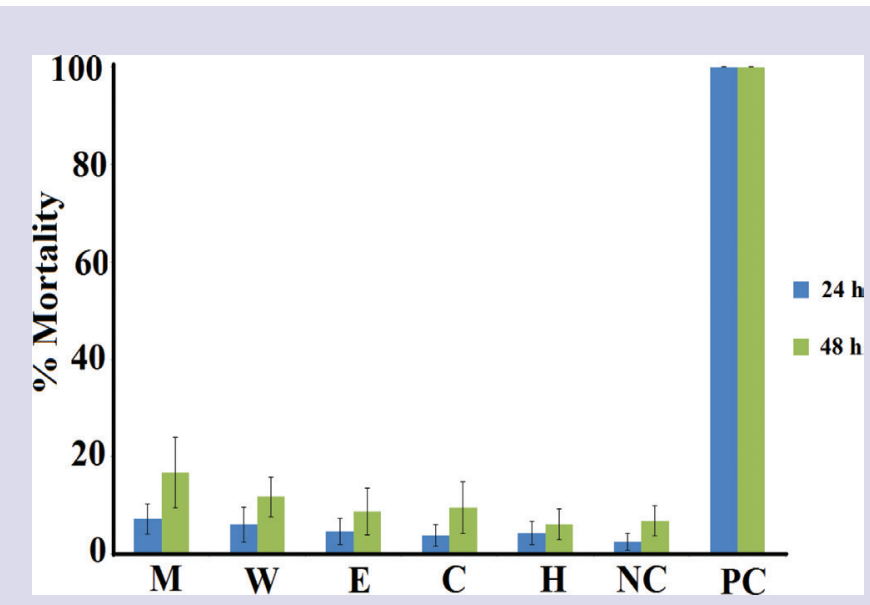

Figure 5: The lethality of the $K$. flavescens leaf extracts $(2000 \mu \mathrm{g} / \mathrm{mL})$, potassium dichromate $(1000 \mu \mathrm{g} / \mathrm{mL})$ and a seawater control.

$\mathrm{M}=$ methanolic extract; $\mathrm{W}=$ aqueous extract; $\mathrm{E}=$ ethyl acetate extract; $\mathrm{C}=$ chloroform extract; $\mathrm{H}=$ hexane extract; $\mathrm{NC}=$ negative (seawater) control; $\mathrm{PC}=$ positive control $(1000 \mu \mathrm{g} / \mathrm{mL}$ potassium dichromate). All bioassays were performed in triplicate and are expressed as mean \pm SEM.

and gram negative bacteria were susceptible towards the K. flavescens leaf extracts although gram positive bacteria were slightly more susceptible (as judged by the \% bacterial species which were inhibited). This is in agreement with many previous studies which have also reported a greater susceptibility of gram positive than gram negative bacterial species towards solvent extracts for South American, ${ }^{37}$ African ${ }^{38}$ and Australian plant extracts. ${ }^{39,40}$

The methanolic $K$. flavescens extract was identified as being a particularly 
potent inhibitor of $P$. mirabilis and K. pneumoniae growth (MIC values of 393 and $481 \mu \mathrm{g} / \mathrm{mL}$ against $P$. mirabilis and $K$. pneumoniae respectively). As $P$. mirabilis can trigger rheumatoid arthritis in genetically susceptible individuals, ${ }^{31,32}$ these extracts have potential for the development of rheumatoid arthritis inhibitory therapies. As K. pneumoniae can trigger ankylosing spondylitis in genetically susceptible individuals, ${ }^{33,34}$ this extract may also be useful in the prevention of ankylosing spondylitis. Similarly, S. pyogenes is a trigger rheumatic heart disease. ${ }^{35,36}$ Thus, the $K$. flavescens leaf extracts have potential in the prevention and treatment of multiple autoimmune inflammatory diseases.

Whilst a detailed investigation of the phytochemistry of the $K$. flavescens leaf extracts was beyond the scope of our study, qualitative screening studies were used to determine the classes of compounds present. Several commonalities were noted: the most potent aqueous, methanolic and ethyl acetate extracts all contained relatively high levels of tannins, phenolics and flavonoids. Many studies have reported potent growth inhibitory activities for a number of tannin compounds. Gallotannins have been reported to inhibit the growth of a broad spectrum of bacterial species ${ }^{41}$ through a variety of mechanisms including binding cell surface molecules including lipotoichoic acid and proline-rich cell surface proteins, ${ }^{42,43}$ and by inhibiting glucosyltransferase enzymes. ${ }^{44}$ Elligitannins are also highly potent inhibitors of bacterial growth, with MIC values as low as $62.5 \mu \mathrm{g} / \mathrm{mL} .{ }^{41,43}$ Ellagitannins have also been reported to function via several antibiotic mechanisms including interaction with cytoplasmic oxidoreductases and by disrupting bacterial cell walls. ${ }^{41,43}$ Thus, it is likely that $K$. flavescens leaf tannins may contribute to the inhibition of bacterial growth reported in our study.

It is likely that other phytochemical classes also contribute to the growth inhibitory properties of these extracts. Our qualitative phytochemical screening studies indicate that polyphenolics and flavonoids were present in relatively high levels in the $K$. flavescens leaf extracts. Many studies have reported potent antibacterial activities for a wide variety of polyphenolic compounds, including many flavonoids. ${ }^{45}$ Further phytochemical evaluation studies and bioactivity driven isolation of active components is required to further evaluate the mechanism of bacterial growth inhibition.

The findings reported here also demonstrate that all of the $K$. flavescens leaf extracts were nontoxic towards Artemia franciscana nauplii, with $\mathrm{LC}_{50}$ values substantially $>1000 \mu \mathrm{g} / \mathrm{mL}$. Extracts with $\mathrm{LC}_{50}$ values $>1000$ $\mu \mathrm{g} / \mathrm{mL}$ towards Artemia nauplii are defined as being nontoxic. ${ }^{30}$ Whilst our preliminary toxicity studies indicate that these extracts may be safe for therapeutic use, studies using human cell lines are required to further evaluate the safety of these extracts. Furthermore, whilst these studies have demonstrated the potential of the K. flavescens leaf extracts in the development of future antibiotic chemotherapeutics for the prevention and treatment of urinary tract infections, autoimmune diseases (particularly rheumatoid arthritis and ankylosing spondylitis) and some skin diseases, more work is required to isolate the inhibitory components and determine the mechanism of inhibition.

\section{CONCLUSIONS}

The results of this study demonstrate the potential of the $K$. flavescens leaf extracts as inhibitors of pathogenic bacteria growth. Furthermore, their lack of toxicity indicates than they are safe for internal as well as topical treatment. Further studies aimed at the purification and identification of bioactive components are needed to examine the mechanisms of action of these agents.

\section{ACKNOWLEDGEMENTS}

The authors are grateful Philip Cameron for providing the $K$. flavescens leaves used in this study, and to Michelle Mendell and Jane Gifkins for the gift of the clinical isolate bacterial strains. Financial support for this work was provided by the Environmental Futures Research Institute and the School of Natural Sciences, Griffith University, Australia.

\section{CONFLICTS OF INTEREST}

The authors report no conflicts of interest.

\section{ABBREVIATIONS}

\section{DMSO: Dimethyl sulfoxide}

$\mathrm{LC}_{50}$ : The concentration required to achieve $50 \%$ mortality

MIC: minimum inhibitory concentration

\section{REFERENCES}

1. Cowan MM. Plant products as antibacterial agents. Clinical Microbiology Reviews 1999; 12: 564-582

2. Bhavnani SM, Ballow CH. New agents for Gram-positive bacteria. Current Opinion in Microbiology 2000; 3: 528-534.

3. Chiariandy CM, Seaforth CE, Phelps RH, Pollard GV, Khambay BP. Screening of medicinal plants from Trinidad and Tobago for antimicrobial and insecticidal properties. Journal of Ethnopharmacology 1999; 64: 265-270.

4. Patwardhan B, Warude D, Pushpangadan P, Bhatt N. Ayurveda and traditional Chinese medicine: a comparative overview. Evidence-based Complimentary and Alternative Medicine 2005; 2: 465-473.

5. Hostettmann K, Marston A, Ndjoko K, Wolfender J. The potential of African plants as a source of drugs. Current Organic Chemistry 2000; 4: 973-1010.

6. Paz EA, Cerdeiras MP, Fernandez J, Ferreira F, Moyna P, Soubes M, Vazquez A, Vero S, Zunino L. Screening of Uruguayan medicinal plants for antimicrobial activity. Journal of Ethnopharmacology 1995; 45: 67-70.

7. Cock IE. Medicinal and aromatic plants - Australia. In Ethnopharmacology, Encyclopedia of Life Support Systems (EOLSS), 2011. Developed under the auspices of UNESCO. Oxford, UK: EOLSS Publishers; 2011. Available from: http://www.eolss.net. Accessed 1 April 2013.

8. Cock IE. Antimicrobial activity of Callistemon citrinus and Callistemon salignus methanolic extracts. 2012 Pharmacognosy Communications 2012; 2 (3): 50-57. DOI: 10.5530/pc.2012.3.11

9. Wright $\mathrm{MH}$, Matthews B, Arnold MSJ, et al. The prevention of fish spoilage by high antioxidant Australian culinary plants: Shewanella putrefaciens growth inhibition. International Journal of Food Science and Technology 2016; DOl: 10.1111/ijfs. 13026

10. Cock IE. Antimicrobial activity of Leptospermum bracteata and Leptospermum juniperium methanolic extracts. Pharmacognosy Communications 2013; 3(3): 45-52. DOI: 10.5530/pc.2013.3.9

11. Cock IE. Antibacterial activity of selected Australian plant species. The Internet Journal of Microbiology 2008; 6: 2.

12. Sautron C, Cock IE. Antimicrobial activity and toxicity of Syzygium australe and Syzygium leuhmanii fruit extracts. Pharmacognosy Communications 2014; 4(1): 53-60. DOI: $10.5530 / p c .2014 .1 .8$

13. Chikowe G, Mpala L, Cock IE. Antibacterial activity of selected Australian Syzygium species. Pharmacognosy Communications 2013; 3 (4): 77-83. DOI: 10.5530/pc.2013.4.11

14. Cock IE. Antimicrobial activity of Syzygium australe and Syzygium leuhmannii methanolic extracts. Pharmacognosy Communications 2012; 2(2): 71-77. DOI: 10.5530/pc.2012.2.11

15. Qiu XD. 2008. Kunzea ambigua chemotypes: their Tasmanian distribution, essential oil ompositon and antimicrobial activities. Masters thesis 2008; University of Tasmania.

16. Takarada K, Kimizuka R, Takahashi N, et al. A comparison of the antibacterial efficacies of essential oils against oral pathogens. Oral Microbiology and Immunology 2004; 19(1): 61-64.

17. Webb MA. Bush Sense. Australian Essential oils and aromatic compounds. Griffin Press, 2000, Adelaide Australia.

18. Thomas J, Narkowicz CK, Jacobson GA. An examination of the essential oils of Tasmanian Kunzea ambigua, other Kunzea spp. and commercial Kunzea oil. Journal of Essential Oil Research 2010; 22(5): 381-385.

19. Boyer $\mathrm{H}$, Cock IE. Evaluation of the potential of Macademia integriflora extracts as antibacterial food agents. Pharmacognosy Communications 2013; 3 (3): 53-62. DOI: $10.5530 / p c .2013 .3 .10$

20. Courtney R, Sirdaarta J, Matthews B, et al. Tannin components and inhibitory 
activity of Kakadu plum leaf extracts against microbial triggers of autoimmune inflammatory diseases. Pharmacognosy Journal 2015; 7(1): 18-31. DOI: 10.5530/pj.2015.7.2

21. Hart C, llanko P, Sirdaarta J, et al. Tasmannia stipitata as a functional food/natural preservative: Antimicrobial activity and toxicity. Pharmacognosy Communications 2014; 4(4): 33-47. DOI: 10.5530/pc.2014.4.4

22. Mpala L, Chikowe G, Cock IE. No evidence of antiseptic properties and low toxicity of selected Aloe species. Journal of Pharmaceutical Negative Results 2010; 1(1): 10-16. DOI: 10.4103/0976-9234.68869

23. Sirdaarda J, Matthews B, White A, et al. GC-MS and LC-MS analysis of Kakadu plum fruit extracts displaying inhibitory activity against microbial triggers of multiple sclerosis. Pharmacognosy Communications 2015; 5 (2): 100-115. DOI: 10.5530/pc.2015.2.2

24. Kalt FR, Cock IE. Gas chromatography-mass spectroscopy analysis of bioactive Petalostigma extracts: Toxicity, antibacterial and antiviral activities. Pharmacognosy Magazine 2014; 10 (Suppl 1): S37-49. DOI: 10.4103/0973-1296.127338

25. Vesoul J, Cock IE. The potential of Bunya nut as an antibacterial food agent Pharmacognosy Communications 2012; 2 (1): 72-79. DOI: 10.5530/pc.2012.1.13

26. Arkhipov A, Sirdaarta J, Rayan $P$, et al. An examination of the antibacterial, antifungal, anti-Giardial and anticancer properties of Kigelia africana fruit extracts. Pharmacognosy Communications 2014; 4(3): 62-76. DOI: 10.5530/pc.2014.3.7

27. Cock IE. Antimicrobial activity of Acacia aulacocarpa and Acacia complanta methanolic extracts. Pharmacognosy Communications 2012; 2(1): 66-71. DOI: 10.5530/pc. 2012.1.12

28. Cock IE. Assessment of the toxicity of selected Australian native plant extracts using the Artemia franciscana nauplii bioassay. Internet Journal of Toxicology 2008; 5: 2

29. Ruebhart DR, Wikramasinghe WA, Cock IE. Protective efficacy of the antioxidants vitamin $\mathrm{E}$ and Trolox against Microcystis aeruginosa and microcystin-LR in Artemia franciscana nauplii. Journal of Toxicology and Environmental Health Part A 2009; 72(24): 1567-1575.

30. Cock IE, Ruebhart DR. Comparison of the brine shrimp nauplii bioassay and the ToxScreen-II test for the detection of toxicity associated with Aloe vera (Aloe barbadensis Miller) leaf extract. Pharmacognosy Research 2009; 1(2): 98-101.

31. Cock IE, van Vuuren SF. Anti-Proteus activity of some South African plants: Their potential for the prevention of rheumatoid arthritis. Inflammopharmacology 2014; 22: 23-36. DOI: 10.1007/s10787-013-0179-3

32. Ebringer A, Rashid T. Rheumatoid arthritis is an autoimmune disease triggered by Proteus urinary tract infection. Clinical and Developmental Immunology 2006; 13 (1): 41-48.
33. Cock IE, van Vuuren SF. The potential of selected South African plants with antiKlebsiella activity for the treatment and prevention of ankylosing spondylitis. Inflammopharmacology 2015; 23: 21-35. DOI: 10.1007/s10787-014-0222-z

34. Ebringer A, Rashid T, Wilson $C$, et al. Ankylosing spondylitis as an auto-immune disease linked to intestinal Klebsiella infection: prospects for a new therapeutic approach. Current Rheumatology Reviews 2006; 2: 55-68.

35. Lee CJ, Wright MH, Arnold MSJ, et al. Inhibition of Streptococcus pyogenes growth by native Australian plants: New approaches towards the management of impetigo, pharyngitis and rheumatic heart disease. Pharmacognosy Communications 2016; 6(3): 164-173. DOI: 10.5530/pc.2016.3.6

36. Wright $\mathrm{MH}$, Arnold MSJ, Lee CJ, et al. Qualitative phytochemical analysis and antibacterial activity evaluation of Indian Terminalia spp. against the pharyngitis causing pathogen Streptococcus pyogenes. Pharmacognosy Communications 2016; 6(2): 82-92. DOI: 10.5530/pc.2016.2.6

37. Mohanty S, Cock IE. Evaluation of the antibacterial activity of Mycaria caulifloria methanolic leaf and fruit extracts. The Internet Journal of Microbiology 2009; $7(2)$

38. Cock IE, van Vuuren SF. South African food and medicinal plant extracts as potential antimicrobial food agents. Journal of Food Science and Technology 2015; 52(11): 6879-6899. DOI: 10.1007/s13197-015-1806-3

39. Cock IE, Kukkonen L. An examination of the medicinal potential of Scaevola spinescens: Toxicity, antibacterial, and antiviral activities. Pharmacognosy Research 2011; 3 (2): 85-94. DOI: 10.4103/0974-8490.81955

40. Vesoul J, Cock IE. An examination of the medicinal potential of Pittosporum phylliraeoides: Toxicity, antibacterial, and antifungal activities. Pharmacognosy Communications 2011; 1 (2): 8-17. DOI: 10.5530/pc.2011.2.3

41. Buzzini $P$, Arapitsas $P$, Goretti $M$, et al. Antimicrobial activity of hydrolysable tannins. Mini-Reviews in Medicinal Chemistry 2008; 8: 1179-1187.

42. Wolinsky LE, Sote EO. Isolation of natural plaque-inhibiting substances from 'Nigerian chewing sticks'. Caries Research 1984; 18: 216-225.

43. Hogg SD, Embery G. Blood-group-reactive glycoprotein from human saliva interacts with lipoteichoic acid on the surface of Streptococcus sanguis cells. Archives in Oral Biology 1982; 27: 261-268.

44. Wu-Yuan CD, Chen CY, Wu RT. Gallotannins inhibit growth, water-soluble glucan synthesis, and aggregation of Streptococci mutans. Journal of Dental Research 1988; 67: 51-55.

45. Cock IE. The phytochemistry and chemotherapeutic potential of Tasmannia lanceolata (Tasmanian pepper): A review. Pharmacognosy Communications 2013; 3(4): 1-13. DOI: 10.5530/pc.2013.4.3

\section{PICTORIAL ABSTRACT}

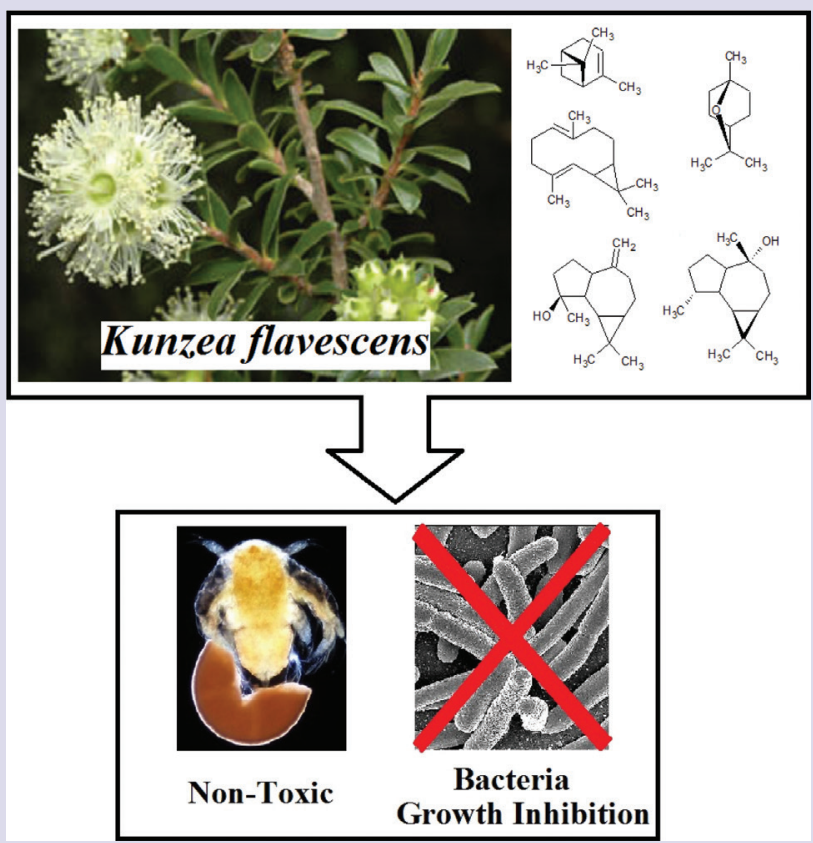

\section{SUMMARY}

- $\quad$ K. flavescens leaf extracts inhibited the growth of both gram positive and gram negative bacteria.

- The methanolic, aqueous and ethyl acetate extracts were potent inhibitors of $P$. mirabilis growth, with MICs $375-850 \mu \mathrm{g} / \mathrm{mL}$.

- The same extracts were also potent inhibitors of $K$. pneumomiae growth, with MICs 480-950 $\mu \mathrm{g} / \mathrm{mL}$.

- The methanolic, aqueous and ethyl acetate extracts were also moderate inhibitors of $A$. hydrophilia, B. cereus and S. pyogenes growth.

- $\quad$ All K. flavescens leaf extracts were nontoxic. 


\section{ABOUT AUTHORS}

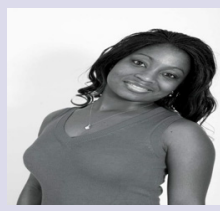

Ms Getmore Chikowe completed at BSc at Griffith University in life sciences. Following graduation, she undertook a research project in Dr lan Cock's laboratory in the School of Natural Sciences at Griffith University. The project examined the growth inhibitory properties of a variety of Australian native plants against an extensive panel of bacterial pathogens.

Ms Lindiwe Mpala completed at BSc at Griffith University in life sciences. Following graduation, she undertook a research project in Dr lan Cock's laboratory in the School of Natural Sciences at Griffith University. The project examined the growth inhibitory properties of a variety of Australian native plants against an extensive panel of bacterial pathogens.

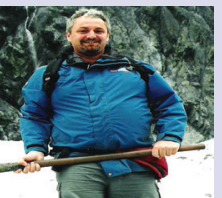

Dr lan Cock leads a research team in the Environmental Futures Research Institute and the School of Natural Scences at Griffith University, Australia. His research involves bioactivity and phytochemical studies into a variety of plant species of both Australian and international origin, including Aloe vera, South Asian and South American tropical fruits, as well as Australia plants including Scaevola spinescens, Pittosporum phylliraeoides, Terminalia ferdinandiana (Kakadu plum), Australian Acacias, Syzygiums, Petalostigmas and Xanthorrhoea johnsonii (grass trees). This range of projects has resulted in nearly 200 publications in a variety of peer reviewed journals. 